\title{
GUM ARABIC: AN OPTIMIZATION OF ULTRASONIC- ASSISTED EXTRACTION OF ANTIOXIDANT ACTIVITY
}

\author{
AHMED. A. M. ELNOUR ${ }^{a}{ }^{b}$, MOHAMED E. S. MIRGHANI ${ }^{a, c, *}$, \\ NASSERELDIN A. KABBASHI ${ }^{a}$, MD Z. ALAM ${ }^{a}$ \\ AND KHALID HAMID MUSA ${ }^{d}$
}

\begin{abstract}
Gum Arabic (GA), also known as Acacia seyal gum (ASG), is a dried exudate from trees of Acacia senegal and Acacia seyal. It provides a rich source of non-viscous soluble fiber with significant health benefits and high antioxidant properties. Tonnes of raw GA are exported annually at a high cost with limited utilization in extraction form. Techniques for the extraction of the bioactive components of GA are available but the high extraction time and the capacity and quality of extraction hinders these procedures. Ultrasonicassisted extraction is one of the most effective techniques for the recovery of antioxidant and phenolic compounds from ASG. A comparatively low extraction time has been reported for ultrasonication, but the influence of several extraction conditions such as temperature, time and ultrasonic power on the yield of extraction has not been thoroughly studied. This study investigates the optimal ultrasonic extraction conditions for maximum recovery of antioxidant and phenolic compounds from ASG using Response Surface Methodology (RSM) under the Central Composite Design (CCD). Three ultrasonic parameters, namely time in the range of (1-3 hours), power in the range of (1-3 level or 12 to $40 \mathrm{kHz})$ and temperature from $\left(25-60{ }^{\circ} \mathrm{C}\right)$ were tested for their impact on antioxidant activity. The capacity of the extracts was determined by the scavenging activity of 1, 1-diphenyl-2picrylhydrazyl (DPPH) radical, ferric reducing antioxidant power (FRAP) assay, and total phenolic compounds (TPC). The results indicated that ultrasonic time, power and temperature had a positive impact on antioxidant capacity and phenolic compounds. The optimum ultrasonic conditions were
\end{abstract}

a Bioenvironmental Engineering Research Centre (BERC), Biotechnology Engineering, Faculty of Engineering, International Islamic University, Malaysia (IIUM), P. O. Box 10, Gombak. 50728 Kuala Lumpur, Malaysia.

b Department of Biochemistry \& Gum Processing, Gum Arabic Research Centre, University of Kordofan, Box: 160. Elobied, Sudan

c International Institute for Halal Research and Training (INHART), IIUM, P. O. Box 10, Gombak. 50728 Kuala Lumpur, Malaysia.

d Department of Food Science and Human Nutrition College of Agriculture and Veterinary Medicine Qassim university, the kingdom of Saudi Arabia.

* Corresponding author: elwathig@iium.edu.my 
found to be a time of 3 hours, a power of $40 \mathrm{kHz}$, and a temperature of $42.50^{\circ} \mathrm{C}$, under which, forty-eight bioactive compounds from the ASG extract were separated by Gas Chromatography coupled to Tandem Mass Spectrometry (GC-MS/MS).

Keywords: Acacia seyal gum, Bioactive compounds, Gum Arabic, Response Surface Methodology, Ultrasonication.

\section{INTRODUCTION}

Gum Arabic (GA) is an edible, dried, gummy biopolymer exudates obtained from trees and branches of Acacia senegal and Acacia seyal. It grows predominantly in the African region of Sahel in Sudan. GA is one of the world's major natural commodities of commerce and constitutes an important export commodity in countries such as Niger, Chad, Senegal, Nigeria, and especially Sudan which controls about $85 \%$ of the world's export of GA [1]. Tones of GA are exported annually and has been estimated to the tune of US $\$ 40$ million yearly over the last 20 years $[1,2]$. Despite the fairly high prices, the supply of and demand for GA have declined steadily over the past few decades due to a number of reasons which bothers (aside from the uncontrollable natural phenomenon) on the regulatory policy to ensure food quality and safety of the raw gum $[1,3]$. Strict international specification based on the microbiological and chemical characteristics of GA and similar products have been instituted to guarantee the identity, quality, and safety of the raw exudates. This poses several trade challenges.

Gum Arabic (GA) produced by the traditional method exhibit high variability in microbiological quality. In its raw form, it is highly susceptible to bacteriological spoilage especially when stored in warehouses [1]. Traditional solutions to ensure that Gum Arabic reaches the end-user in good quality are expensive.

Spray-drying, for instance, which is a form of pasteurization of the gum through controlled exposure to high temperature, is an energy-intensive and costly procedure estimated at the US $\$ 1000$ per ton [1]. Marketing GA to its end users is therefore costly, often requires a long chain of mediators, and mostly require further processing by its end users [4].

Chemically, GA is a complex mixture of macromolecules of different sizes and composition - mainly carbohydrates and proteins. It is rich in nonviscous soluble fibers with high dietary value, and also contains minerals like potassium, magnesium and calcium [5-8].GA antioxidant properties, nephroprotectant, and other effects have been highlighted in recent studies [9-11]. Its role in the metabolism of lipids $[12,13]$, and its positive effect in the 
treatment of several degenerative diseases such as kidney failure [14-16], cardiovascular [17] and gastrointestinal diseases [18, 19] have also been reported. GA, therefore, promises a lot of benefits in medical, food, and pharmaceutical industries.

The major concern about GA, however, is the need to maintain the supply and demand chain of GA in a cost-effective way, and to ensure the purity, quality, and safety of GA that reached the end-users. Extraction of the bioactive components from GA suggests a viable approach to resolve these concerns. A powdered bioactive component of GA extract can prove costeffective by minimizing tons of exported raw GA, and can also allow standardization of the quality and purity of GA. A big challenge, however, is that sufficient data for an efficient extract procedure of the antioxidant or bioactive component of GA are sparse.

Various techniques exist for extraction of antioxidants from plant materials and other foodstuffs. The techniques commonly adopted are shaking, homogenization at high speed, maceration, and stirring. A comprehensive experimental comparison of this techniques has not been reported, however, some studies have highlighted the drawbacks in these techniques to include low product quality, safety hazards, and prolonged extraction time [20].

Recently, novel extraction techniques such as microwave-assisted, ultrasonic-assisted, and enzyme-assisted super-critical fluid extraction technique have also been developed for extraction of antioxidants from plant materials [21-23]. The novel techniques have shown remarkable improvement in the extraction process but have also come with some drawbacks. For instance, the enzyme-assisted supercritical extraction is reported to be highly eco-friendly but requires a low range of temperature at a high cost [24]. The incurred high cost appears the major challenge in these techniques.

The ultrasonic-assisted extraction (UAE) is overall considered the most economical and efficient extraction methods of the newly introduced techniques [25-29]. It has been successfully applied for the extraction of antioxidant from plant materials; however, its implementation depends significantly on the condition of extraction. An appropriate choice of UAE extraction parameters such as ultrasonic power, temperature, and time should reasonably influence the yield of extraction.

This study aims to design an optimized ultrasonic-assisted extraction for the preparation of antioxidant powder from raw gum arabic using response surface method (RSM). Response surface method (RSM) is a mathematical and statistical tool, which has been widely used to optimize various parameters in process industries [30]. It has been used recently to determine the most influential parameters for simultaneous production of lactic acid, xanthan and 
ethanol from molasses [31-34]. RSM can evaluate the impact of different multiple parameters, and simultaneously optimize experimental conditions [35-37]. Different RSM methods such as box-Behnken design (BBD), central composite design (CCD) and three-level full factorial designs (TFFD) have been used widely in various fields such as food, biology and chemistry. Although the CCD, which has been proven for its accurate fitness in different models and experiments, is more commonly adopted for RSM [32].

In this experimental study, UAE parameters namely power, time and temperature of extraction were optimized by RSM, adopting the central composite design (CCD), to obtain optimal extraction of total phenolic contents and antioxidant activity from ASG. To the best of the Authors' knowledge, this is the first time the RSM has been deployed to optimize UAE parameters for optimal extraction of total phenolic compounds and antioxidant activity from GA. We also identified the composition of the extracts by GC-MS/MS and assessed the influence of ultrasound on the extraction efficiency and chemical compositions of the extracts.

\section{RESULTS AND DISCUSSION}

\section{FITTING THE MODEL}

Twenty experiments were conducted under different conditions of ultrasonic extraction. Overall, the antioxidant activities or responses for the independent variables of ultrasonic-assisted extraction were recorded as shown in Table 1. The experiment labelled ' 8 ' with a total ultrasonic extraction time of $3 \mathrm{~h}$, extraction power of $40 \mathrm{kHz}$, and temperature of $60^{\circ} \mathrm{C}$ was found to produce the highest DPPH inhibition of $89.2 \%$, FRAP of $26646 \mathrm{mg} \mathrm{TE} / 100 \mathrm{~g}$ DW, and total phenolic content (TPC) of $25145 \mathrm{mg}$ GAE/100g DW. In contrast, the experiment labelled ' 1 ' with an extraction time of $1 \mathrm{~h}$, power of $12 \mathrm{kHz}$, and temperature of $25^{\circ} \mathrm{C}$ produced the least responses with DPPH inhibition of $35.5 \%$, FRAP of $6430 \mathrm{mg}$ TE/100g DW and TPC of $4694 \mathrm{mg} \mathrm{GAE} / 100 \mathrm{~g} \mathrm{DW}$.

\section{ANALYSIS OF VARIANCE}

In the prediction of optimized ultrasonic assisted extraction conditions for the DPPH, FRAP and TPC assays, it is important to check the fitting of the RSM mathematical model to ensure its reliability. Different techniques for analysis of variance, such as lack of fit; $R^{2}$; Predicted Residual Sum of Square (PRESS) for models; F-ratio; and Prob > F methods were analyzed to identify the fitting of the RSM mathematical models. "Lack of fit" assesses the model for appropriate effects when the test is conducted. $R^{2}$ estimates the proportion of 
variation in the response that can be attributed to the model rather than to random errors. An $R^{2}$ value near 1 indicates that the model is a good predictor of the response. PRESS shows how well the predictive model fits each point in the design. The F-ratio indicates whether the model differs significantly from a model where all predicted values are the response mean. Prob > F measures the probability of obtaining an F-ratio as large as what is observed, given that all parameters except the intercept are zero. Small values of Prob $>$ F indicate that the observed F-ratio is unlikely. Such values are considered evidence that there is at least one significant effect in the model [30].

Table 1. Antioxidant activities, of the extract of $A$. seyal gum under different conditions of ultrasonic-assisted extraction based on a central composite design

(CCD) for response surface analysis.

\begin{tabular}{|l|c|c|c|c|c|c|}
\hline & \multicolumn{3}{|c|}{ Extraction Condition } & \multicolumn{3}{c|}{ Analytical results } \\
\cline { 2 - 7 } Run & $\begin{array}{c}\mathbf{X}_{2} \text { Extraction } \\
\text { time (hours) }\end{array}$ & $\begin{array}{c}\mathbf{X}_{2} \text { Extraction } \\
\text { power (kHz) }\end{array}$ & $\begin{array}{c}\text { X2 Extraction } \\
\text { Temperature } \\
\text { ('C) }\end{array}$ & $\begin{array}{c}\text { Antioxidan } \\
\text { DPPH } \\
\text { t Activity } \\
\text { FRAP (mibition } \\
\text { TE/100g } \\
\text { DW) }\end{array}$ & $\begin{array}{c}\text { Total } \\
\text { phenolic } \\
\text { Content (mg } \\
\text { GAE/100g } \\
\text { DW) }\end{array}$ \\
\hline $\mathbf{1}$ & $1(-1)$ & $12(-1)$ & $25(-1)$ & 35.5 & 6430 & 4694 \\
\hline $\mathbf{2}$ & $3(1)$ & $12(-1)$ & $25(-1)$ & 43.2 & 7607 & 5876 \\
\hline $\mathbf{3}$ & $1(-1)$ & $40(1)$ & $25(-1)$ & 46.8 & 8254 & 5862 \\
\hline $\mathbf{4}$ & $3(1)$ & $40(1)$ & $25(-1)$ & 57.2 & 17183 & 11798 \\
\hline $\mathbf{5}$ & $1(-1)$ & $12(-1)$ & $60(1)$ & 58.4 & 10298 & 6770 \\
\hline $\mathbf{6}$ & $3(1)$ & $12(-1)$ & $60(1)$ & 83.3 & 26646 & 18307 \\
\hline $\mathbf{7}$ & $1(-1)$ & $40(1)$ & $60(1)$ & 56.5 & 11369 & 8963 \\
\hline $\mathbf{8}$ & $3(1)$ & $40(1)$ & $60(1)$ & 89.2 & 26646 & 25145 \\
\hline $\mathbf{9}$ & $1(-1.68179)$ & $26(0)$ & $42.5(0)$ & 55.4 & 9860 & 7406 \\
\hline $\mathbf{1 0}$ & $3(1.68179)$ & $26(0)$ & $42.5(0)$ & 70.7 & 17451 & 12768 \\
\hline $\mathbf{1 1}$ & $2(0)$ & $12(-1.68179)$ & $42.5(0)$ & 78.2 & 15740 & 12201 \\
\hline $\mathbf{1 2}$ & $2(0)$ & $40(1.68179)$ & $42.5(0)$ & 80.9 & 14592 & 12194 \\
\hline $\mathbf{1 3}$ & $2(0)$ & $26(0)$ & $25(-1.68179)$ & 81.5 & 13452 & 10814 \\
\hline $\mathbf{1 4}$ & $2(0)$ & $26(0)$ & $60(1.68179)$ & 86.2 & 24995 & 17413 \\
\hline $\mathbf{1 5}$ & $2(0)$ & $26(0)$ & $42.5(0)$ & 56.6 & 23141 & 15575 \\
\hline $\mathbf{1 6}$ & $2(0)$ & $26(0)$ & $42.5(0)$ & 79.9 & 18560 & 13622 \\
\hline $\mathbf{1 7}$ & $2(0)$ & $26(0)$ & $42.5(0)$ & 83.4 & 19887 & 13704 \\
\hline $\mathbf{1 8}$ & $2(0)$ & $26(0)$ & $42.5(0)$ & 83.9 & 17380 & 13342 \\
\hline $\mathbf{1 9}$ & $2(0)$ & $26(0)$ & $42.5(0)$ & 79.7 & 19158 & 13745 \\
\hline $\mathbf{2 0}$ & $2(0)$ & $26(0)$ & $42.5(0)$ & 55.3 & 16503 & 12133 \\
\hline & & & & \\
\hline
\end{tabular}

${ }^{*}$ All results are the means $\pm S D(n=3)$. 
Tables 2 - 4 present the analysis of variance for fitting the mathematical models used in the prediction of optimized ultrasonic extraction conditions. The results showed that the coefficient of determination $\left(R^{2}\right)$ of the models for all three responses (DPPH, FRAP and TPC) was close to 1 (ranging between 0.8117 and 0.9583 ), which imply that the mathematical models are reliable predictors for DPPH, FRAP and TPC assays. The $R^{2}$ values indicate that at least $81 \%$ of the actual values were matched with the predicted values proposed by the mathematical models. The results also outlined that "lack of fit" of the models for DPPH, FRAP and TPC were all significantly higher than 0.05 indicating that the models had the appropriate effects when the experiments were conducted. In addition, the "Prob > F" values were found to be in the range of 0.0001 and 0.9988 , and the F-ratio of the models were found to be low which further confirm that the RSM models adopted in the study were reliable in the prediction of optimal ultrasonic extraction conditions for DPPH, FRAP and TPC.

Table 2. ANOVA for DPPH fitted quadratic polynomial model of extraction parameter

\begin{tabular}{|l|l|l|l|l|l|l|}
\hline \multicolumn{1}{|c|}{ Source } & $\begin{array}{c}\text { Sum of } \\
\text { Squares }\end{array}$ & DF & $\begin{array}{c}\text { Mean } \\
\text { Squares }\end{array}$ & $\begin{array}{c}\text { F - (Ratio) } \\
\text { Value }\end{array}$ & p-value & Significant \\
\hline Model & 4184.98 & 6 & 697.5 & 9.34 & $0.0004^{\star \star}$ & Significant \\
\hline$X_{1}$-time & 825.07 & 1 & 825.07 & 11.05 & $0.0055^{\star}$ & \\
\hline$X_{2}$-power & 102.3 & 1 & 102.3 & 1.37 & 0.2628 & \\
\hline$X_{3}$-temperature & 1566.66 & 1 & 1566.66 & 20.98 & $0.0005^{\star \star}$ & \\
\hline$X_{1} X_{2}$ & 195.26 & 1 & 195.26 & 2.62 & 0.1298 & \\
\hline$X_{2} X_{2}$ & 57.03 & 1 & 57.03 & 0.76 & 0.398 & \\
\hline$X_{1}^{2}$ & 1641.69 & 1 & 1641.69 & 21.99 & $0.0004^{\star \star}$ & \\
\hline Residual & 970.55 & 13 & 74.66 & & & \\
\hline Lack of Fit & 108.4 & 8 & 13.55 & 0.079 & 0.9988 & Not significant \\
\hline Pure Error & 862.15 & 5 & 172.43 & & & \\
\hline Cor Total & 5155.53 & 19 & & & & \\
\hline R-squared & & & & 0.8117 & & \\
\hline Adj R-squared & & & & 0.7249 & & \\
\hline
\end{tabular}

$*(C . V=12 \%), P R E S S=1532.95$

${ }^{*} \mathrm{P} \leq 0.05$ indicates the model terms are significant.

${ }^{* *} \mathrm{P} \leq 0.01$ indicates the model terms are highly significant. 


\section{THE DPPH RESPONSE SURFACE ANALYSIS OF ANTIOXIDANT ACTIVITY}

The effects of factors such as extraction time, power, and temperature, denoted $x_{1}, x_{2}$ and $x_{3}$ respectively in equation (3) were carefully studied. The significance of each coefficient was determined by F-values and $\mathrm{p}$-values. The regression equation in coded level, neglecting insignificant terms, was generated as:

$$
\begin{gathered}
\text { DPPH\%= }+77.78+9.08 x_{1}+3.20 x_{2}+11.99 x_{3}+4.94 x_{1} x_{3}-2.67 x_{2} x_{3} \\
-18.16 x_{1}^{2}
\end{gathered}
$$

Results indicated that the quadratic relationship between the DPPH inhibition and extraction factors have a good regression coefficient $\left(R^{2}=\right.$ 0.8117). Higher F-value with lower $p$-value always led to more significant correspondence amongst the independent variables. The terms $x_{1}, x_{2}, x_{3}$ $x_{1} x_{3}$ and $x_{1}^{2}$ were significant with a $p$-value less than 0.05 . However, $x_{1}, x_{2}$ and $x_{2}^{2} x_{3}^{2}$, were not significant due to a higher $p$-value (i.e. higher than 0.05 ).

Figure 1 showed the complex interaction between time, temperature, and extraction power. The highest anti-scavenging activity (DPPH) was observed at both higher time of extraction and lower temperature (see Figure 1A). However, the increase in temperature at a fixed extraction time led to an increase in the extraction of antioxidant activity using DPPH assay. The extraction reached a maximum but at the lowest temperature tested. Figure $1 \mathrm{~B}$ showed the interaction between the temperature and time of extraction on the antioxidant scavenging (DPPH \%). An increase in the antioxidant activity was noticed as the extraction temperature increased up to $60^{\circ} \mathrm{C}$, but decreased thereafter. A significant increase in the antioxidant capacity was also observed at high ultrasonic power. However, the trend was reversed as the ultrasonic power reached the third level at $40 \mathrm{kHz}$ (see Fig 1C). High temperature might decrease the antioxidants activity due to the increase of thermal effect or due to degradation of bioactive compounds. High temperatures degrade phenolic compounds, leading to a reduction in the antioxidants [32, 38, 39]. 


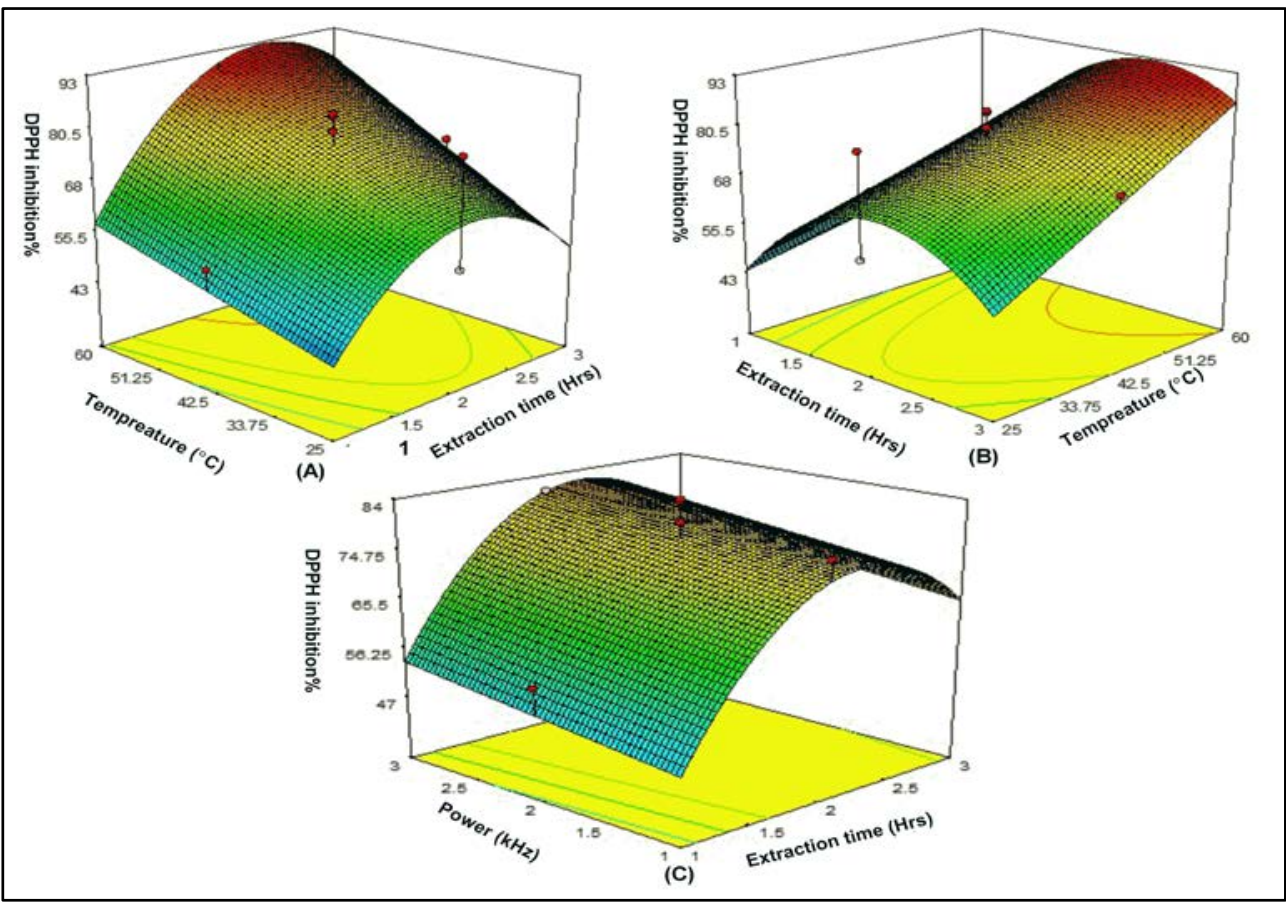

Figure 1. 3D Response surface plots showing the operating parameter effect on antioxidant capacity. (A) The DPPH \% vs. extraction time of $3 \mathrm{~h}$ and ultrasonic power of $40 \mathrm{kHz}$ at fixed temperature of $42.50^{\circ} \mathrm{C}$; (B) The DPPH vs. temperatures ${ }^{\circ} \mathrm{C}$ and extraction time of $3 \mathrm{~h}$, at ultrasonic power of $40 \mathrm{kHz}$; (C) The DPPH\% vs extraction time of $3 \mathrm{~h}$ and ultrasonic power of $40 \mathrm{kHz}$ at fixed temperature of $42.50^{\circ} \mathrm{C}$.

\section{THE FRAP RESPONSE SURFACE ANALYSIS OF ANTIOXIDANT ACTIVITY}

Results for FRAP response surface analysis of the antioxidant activity of Acacia seyal gum (ASG) is presented in Table 3 . The regression value $\left(R^{2}\right.$ $=0.9234$ ) indicates a good relationship between the antioxidant activity of Acacia seyal gum (ASG) and the extraction parameters (time, power and temperature). The fitting quadratic polynomial equation of the data with only significant terms is given in equation (4). 


$$
\begin{aligned}
\text { FRAP } & (\mathrm{mgTE} / 100 \mathrm{gDW})= \\
& 18763.56+6932.07 x_{1}+1132.07 x_{2}+4646.15 x_{3}+834.98 x_{1} x_{2} \\
& +2689.90 x_{1} x_{3}-1291.14 x_{2} x_{3}-4029.61 x_{1}^{2}-2519.61 x_{2}^{2} \\
& +1820.71 x_{2}^{2}
\end{aligned}
$$

where the variables are as defined as in table (3)

Figure 2 shows the relationship between the antioxidant activity and the extraction parameters. The effect of varying extraction time, ultrasonic power and their mutual interaction on the antioxidant activity are shown in Figure 2A. Antioxidant activity increased with increasing ultrasonication power but at high extraction time. The highest antioxidant activity was however observed at extraction time of 3 hours and ultrasonic power of 40 $\mathrm{kHz}$ (levels 3). The effects of extraction time, power and their interaction on antioxidants activity were shown in Figure 2B.

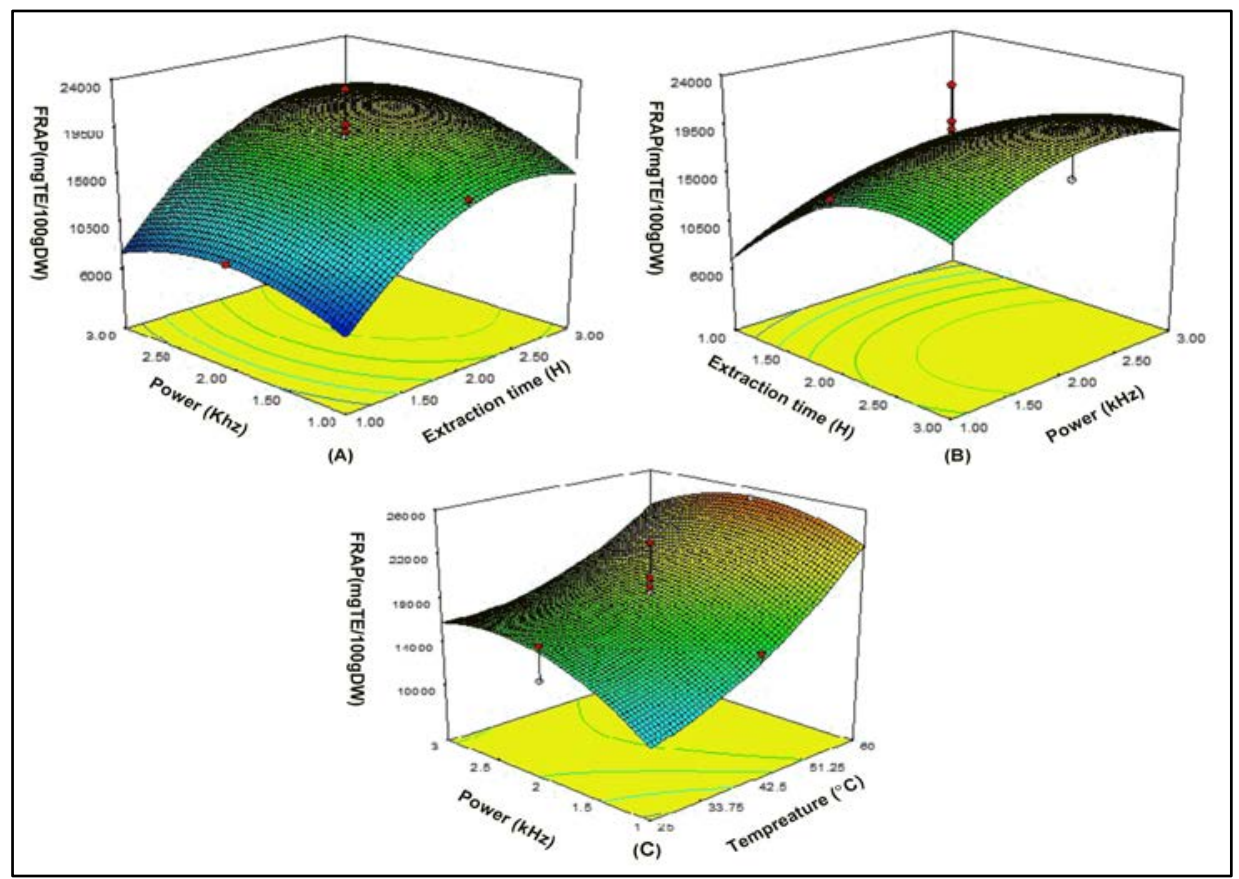

Figure 2. 3D Response surface plots showing the operating parameter effect on antioxidant capacity. (A) The FRAP vs. extraction time of $3 \mathrm{~h}$ and ultrasonic power of $40 \mathrm{kHz}$ at fixed temperature of $42.50^{\circ} \mathrm{C}$; (B) The FRAP vs. ultrasonic power of $40 \mathrm{kHz}$ and Extraction time of $3 \mathrm{~h}$ at fixed temperature of $42.50^{\circ} \mathrm{C} ;(\mathrm{C})$ The FRAP vs extraction temperature of $42.50^{\circ} \mathrm{C}$ at fixed extraction time of $3 \mathrm{~h}$. 
Figure 2C shows the effect of varying the extraction power and temperature on the antioxidants activity. Notice that, at low temperature, less than $42.50^{\circ} \mathrm{C}$, increasing the extraction power resulted in the high amount of antioxidant extraction from ASG. Whereas, at an overheated temperature (greater than $42.50{ }^{\circ} \mathrm{C}$ ), the reverse trend is noticeable. Moreover, higher extraction temperature can produce increasingly repulsive diffusion-solvent interaction, leading to a reduction of antioxidants in the extract. The highest antioxidant activity of ASG extracts was therefore determined at $42.50^{\circ} \mathrm{C}$ for 3 hours.

Table 3. ANOVA for FRAP fitted quadratic polynomial model of Extraction parameter

\begin{tabular}{|c|c|c|c|c|c|c|}
\hline Source & $\begin{array}{l}\text { Sum of } \\
\text { Squares }\end{array}$ & DF & $\begin{array}{c}\text { Mean } \\
\text { Squares }\end{array}$ & F -Value & p-value & Significant \\
\hline Model & $6.62 \mathrm{E}+08$ & 9 & $7.35 \mathrm{E}+07$ & 13.39 & $0.0002^{\star \star}$ & Significant \\
\hline$x_{1}$-time & $2.43 E+08$ & 1 & $2.43 E+08$ & 44.3 & $<0.0001^{\star *}$ & \\
\hline$x_{2}$-power & $1.28 \mathrm{E}+07$ & 1 & $1.28 \mathrm{E}+07$ & 2.34 & 0.1575 & \\
\hline$X_{3}$-temperature & $2.31 E+08$ & 1 & $2.31 E+08$ & 42.12 & $<0.0001^{\star \star}$ & \\
\hline$x_{1} X_{2}$ & $5.58 E+06$ & 1 & $5.58 \mathrm{E}+06$ & 1.02 & 0.3373 & \\
\hline$x_{1} x_{3}$ & $5.79 E+07$ & 1 & $5.79 \mathrm{E}+07$ & 10.54 & $0.0088^{\star \star}$ & \\
\hline$x_{2} x_{3}$ & $1.33 E+07$ & 1 & $1.33 \mathrm{E}+07$ & 2.43 & 0.1502 & \\
\hline$X_{1}^{2}$ & 4.73E+07 & 1 & $4.73 \mathrm{E}+07$ & 8.62 & $0.0149 *$ & \\
\hline$x_{2}^{2}$ & $1.85 \mathrm{E}+07$ & 1 & $1.85 \mathrm{E}+07$ & 3.37 & 0.0962 & \\
\hline$x_{3}^{2}$ & $1.11 \mathrm{E}+07$ & 1 & $1.11 \mathrm{E}+07$ & 2.01 & 0.1864 & \\
\hline \begin{tabular}{|l} 
Residual \\
\end{tabular} & $5.49 \mathrm{E}+07$ & 10 & $5.49 \mathrm{E}+06$ & & & \\
\hline Lack of Fit & $3.14 \mathrm{E}+07$ & 5 & $6.29 \mathrm{E}+06$ & 1.34 & 0.3783 & Not significant \\
\hline Pure Error & $2.35 \mathrm{E}+07$ & 5 & $4.70 \mathrm{E}+06$ & & & \\
\hline Cor Total & 7.17E+08 & 19 & & & & \\
\hline R-squared & & & & 0.9234 & & \\
\hline Adj R-squared & & & & 0.8544 & & \\
\hline
\end{tabular}

* CV=14.41\%. PRESS=374100000.

${ }^{*} \mathrm{P} \leq 0.05$ indicates the model terms are significant.

${ }^{* *} \mathrm{P} \leq 0.01$ indicates the model terms are highly significant.

\section{THE TPC RESPONSE SURFACE ANALYSIS OF ANTIOXIDANT ACTIVITY}

For Total Phenolic Content (TPC), the fitting regression equation in coded level, neglecting insignificant terms was generated as given in equation (5). 
TPC $\quad(m g G A E / 100 g D W)=$

$$
\begin{aligned}
& +13650.06+4019.18 x_{1}+1611.34 x_{2}+3671.68 x_{3}+1174.86 x_{2} x_{3}+2575.14 x_{1} x_{3} \\
& -3129.30 x_{1}-1018.64 x_{2}^{2}+1316.29+1316.29 x_{3}^{2}
\end{aligned}
$$

Where; the variables are as defined as in Table (4).

Results from experimentation (see, Table 4) indicate that the quadratic relationship between TPC and the extraction factors have a good regression coefficient $\left(R^{2}=0.8117\right)$. Terms with $x_{1} x_{2}$ and $x_{1}^{2}$ were not significant due to a higher $p$-value (i.e. higher than 0.05) and were eliminated. Figure 3 shows the plot of the complex interaction between extraction time, ultrasonication power, and extraction temperature.

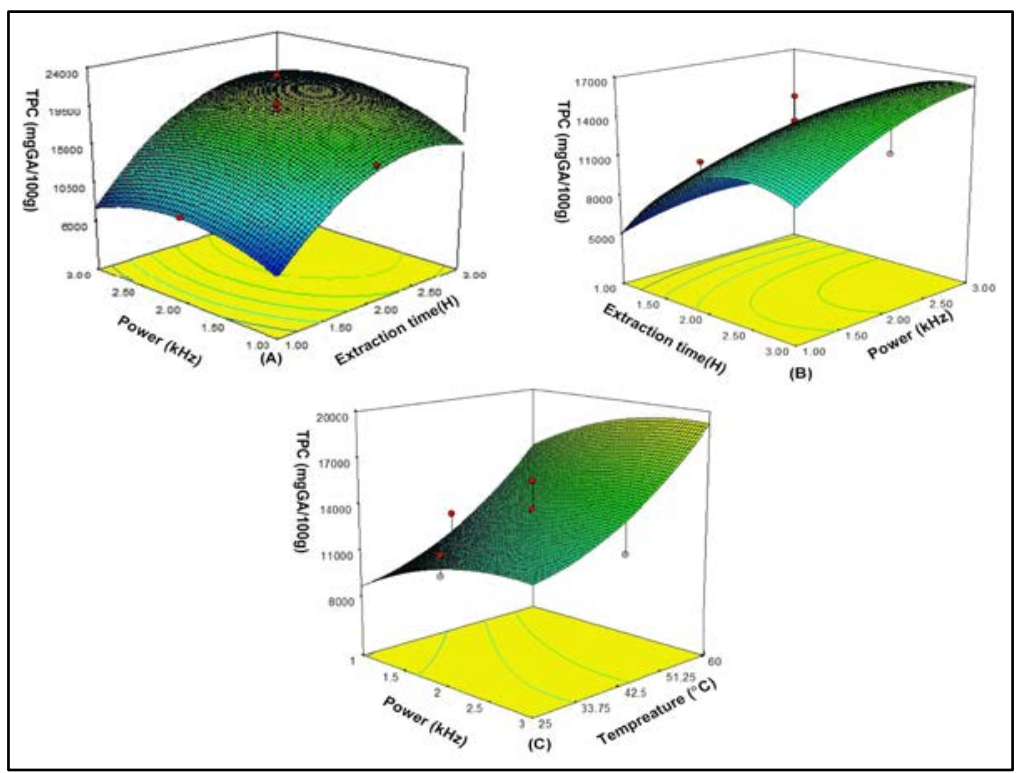

Figure 3. 3D response surface plots showing the operating parameter effect on antioxidant capacity. (A) The TPC (mg GAE/ $100 \mathrm{~g} \mathrm{DW}$ ) vs. extraction time of $3 \mathrm{~h}$ and Ultrasonic power of $40 \mathrm{kHz}$ at fixed temperature of $42.50{ }^{\circ} \mathrm{C}$;(B) The TPC (mg GAE/100g DW) vs. ultrasonic power of $40 \mathrm{kHz}$ and extraction time of $3 \mathrm{~h}$ at fixed temperature of $42.50^{\circ} \mathrm{C}$; (C) The TPC (mg GAE/100g DW) vs extraction temperature $42.50^{\circ} \mathrm{C}$ and ultrasonic power of $48 \mathrm{kHz}$ at fixed extraction time of $3 \mathrm{~h}$.

The highest total phenolic contents were observed at higher extraction time and ultrasonication power as shown in Figure 3A. Increase in both ultrasonication power and extraction time under a fixed temperature resulted in an increase in the total phenolic contents. However, a maximum is reached at the lowest extraction temperature in the range of temperature studied. 
Figure 3B shows the interaction between ultrasonication power and extraction time on total phenolic extraction. Low total phenolic contents were observed for extraction time less than 3 hours but increased for higher time duration. A slight increase in the total phenolic contents at the low ultrasonic power and at higher extraction temperature was also noticed, however, the trend was reversed as the extraction temperature approached $42.50^{\circ} \mathrm{C}$ (see Figure $3 \mathrm{C}$ ). High temperature can reduce the polyphenolic contents as reported in the work of MA, Chen [40] which attributes the reduction to thermal degradation or polymerization reaction of phenols. Also, low ultrasonic power can result in less antioxidant activity due to low cavitations bubble size which has a negative impact on external and internal resistance to mass transfer of gum extraction [41].

Table 4. ANOVA for TPC fitted quadratic polynomial model of Extraction parameter.

\begin{tabular}{|c|c|c|c|c|c|c|}
\hline Source & $\begin{array}{l}\text { Sum of } \\
\text { Squares }\end{array}$ & DF & $\begin{array}{l}\text { Mean } \\
\text { Squares }\end{array}$ & $\begin{array}{l}\text { F - (Ratio) } \\
\text { Value }\end{array}$ & $p$-value & Significant \\
\hline Model & 4184.98 & 6 & 697.5 & 9.34 & $0.0004^{\star \star}$ & Significant \\
\hline$x_{1}$-time & 825.07 & 1 & 825.07 & 11.05 & $0.0055^{\star}$ & \\
\hline$X_{2}$-power & 102.3 & 1 & 102.3 & 1.37 & 0.2628 & \\
\hline$x_{3}$-temperature & 1566.66 & 1 & 1566.66 & 20.98 & $0.0005^{\star \star}$ & \\
\hline$x_{1} X_{2}$ & 195.26 & 1 & 195.26 & 2.62 & 0.1298 & \\
\hline$x_{2} x_{2}$ & 57.03 & 1 & 57.03 & 0.76 & 0.398 & \\
\hline$x_{1}^{2}$ & 1641.69 & 1 & 1641.69 & 21.99 & $0.0004^{\star \star}$ & \\
\hline Residual & 970.55 & 13 & 74.66 & & & \\
\hline Lack of Fit & 108.4 & 8 & 13.55 & 0.079 & 0.9988 & Not significant \\
\hline Pure Error & 862.15 & 5 & 172.43 & & & \\
\hline Cor Total & 5155.53 & 19 & & & & \\
\hline R-squared & & & & 0.8117 & & \\
\hline Adj R-squared & & & & 0.7249 & & \\
\hline
\end{tabular}

${ }^{\star} \mathrm{C} . \mathrm{V}=10.81 \%$; PRESS $=453100000$.

${ }^{*} \mathrm{P} \leq 0.05$ indicates the model terms are significant.

${ }^{* *} \mathrm{P} \leq 0.01$ indicates the model terms are highly significant

\section{OPTIMIZATION AND VALIDATION OF ULTRASONIC EXTRACTION CONDITIONS}

Based on the foregoing mathematical models, the predictions of optimal ultrasonic conditions for antioxidant activity of ASG (using DPPH, FRAP, and TPC assay) are a time of 3hours, a power of $40 \mathrm{kHz}$ and a temperature of $42.50^{\circ} \mathrm{C}$. To validate these predictions, the actual experiment 
was conducted keeping the ultrasonic conditions at these optimal. The experiment was repeated three times and the results averaged. Table 5 gives the comparison between the actual and predicted the antioxidant activity of ASG. The results indicate a close similarity between the experiment and the predicted values $(p \geq 0.05)$, with prediction errors approximately $6.2 \%$ for both DPPH and FRAP assays and $14 \%$ for TPC. This shows that for maximum recovery of polyphenolic compounds and antioxidant capacity from ASG, the applied ultrasonic conditions can be considered optimal. For both prediction and experiment, the antioxidant activities observed using FRAP was larger than that of TPC. The DPPH inhibition was less than that for FRAP and TPC, despite DPPH being a more stable antioxidant assay [42, 43].

Table 5. Validation of the predicted values for antioxidant properties

\begin{tabular}{|l|l|l|}
\hline \multirow{2}{*}{ Antioxidant activity } & \multicolumn{2}{c|}{ Values } \\
\cline { 2 - 3 } & Predicted & Experimental $(\mathbf{n}=\mathbf{3})$ \\
\hline DPPH (inhibition \%) & $74.9708 \pm 9.91^{\mathrm{a}}$ & $70.55 \pm 0.97^{\mathrm{a}}$ \\
\hline FRAP (mgTE/100g) & $20499.4 \pm 3006.25^{\mathrm{a}}$ & $19303.54 \pm 231^{\mathrm{a}}$ \\
\hline TPC(GAE/100g) & $17714 \pm 1677.75^{\mathrm{a}}$ & $15406.97 \pm 130.05^{\mathrm{a}}$ \\
\hline
\end{tabular}

All the values are means \pm standard deviations and those in the same row not sharing the same superscript letter (a) are significantly different from each other $(p \leq 0.05)$.

\section{CHEMICAL COMPOSITION OF OPTIMIZED ASG ANTIOXIDANT EXTRACT}

Forty-eight components from the ASG extract were separated using the predicted optimum conditions as shown in Figure 4. The major components identified by GC-MS/MS were Isovitamin C (42.37\%), Crypton (5.86\%), Hydroquinone (4.8\%), and Thiazolidin-4-one,5-ethyl-2-imino (2.49\%). Table 6 presents the complete list of bioactive components from the ASG extract.

Similar studies were reported which consider the total phenolic contents and antioxidant values [32, 44, 45], however, unlike the current study, there was the detectable amount of hydroxybenzaldehyde, luteolin/ kaempferol, feruloyl-arabinose-arabinose and caffeoyltartaric acid which are not present in this experiment. The amount of isovitamin $\mathrm{C}$ determined in the current study was higher than the amount reported by Fiorito et al [45]. Overall, some bioactive components namely Cyanidin cation, gallic acid, chromone, 5-hydroxy-6,7,8trimethoxy-2,3-dimethyl-, $\quad$ 2,3,5,5,8a-Pentamethyl-6,7,8a-tetrahydro-5Hchromen-8-ol identified in this study have not been reported in previous literature. 
Table 6. The chemical composition of the Acacia seyal gum extracts using optimum conditions to detect the bioactive compounds achieved by GC-MS/MS.

\begin{tabular}{|c|c|c|c|c|c|c|c|}
\hline NO & $\begin{array}{c}\text { RT } \\
(\min )\end{array}$ & $\begin{array}{l}\text { Name of Bioactive } \\
\text { compounds }\end{array}$ & $\begin{array}{c}\text { Area } \\
\text { sum } \\
\%\end{array}$ & NO & $\begin{array}{l}\text { RT } \\
(\min )\end{array}$ & $\begin{array}{l}\text { Name of Bioactive } \\
\text { compounds }\end{array}$ & $\begin{array}{c}\text { Area } \\
\text { sum } \\
\%\end{array}$ \\
\hline 1 & 3.106 & 4-Methylcatechol & 1.42 & 25 & 12.437 & Coniferyl aldehyde & 1.3 \\
\hline 2 & 3.161 & \begin{tabular}{|l|} 
2,5-Diamino-4.6- \\
dihydroxypyrimidine
\end{tabular} & 1.65 & 26 & 12.531 & \begin{tabular}{|l|} 
2,4-Di-tert- \\
butylphenol
\end{tabular} & 1.1 \\
\hline 3 & 3.564 & $\begin{array}{l}\text { Thiazolidin-4-0ne,5-ethyl-2- } \\
\text { imino }\end{array}$ & 2.49 & 27 & 13.036 & o-Cresol,6-tert-butyl & 0.9 \\
\hline 4 & 4.032 & Albuterol & 0.47 & 28 & 15.024 & $\begin{array}{l}\text { 2,6-Dimethylol-p- } \\
\text { cresol }\end{array}$ & 2.16 \\
\hline 5 & 4.545 & 4-Methoxycinnamic acid & 1.11 & 29 & 15.528 & Isovitamine C & 42.37 \\
\hline 6 & 4.694 & Acetophenone,4'-ethyl & 0.91 & 30 & 15.708 & Cyanidin cation & 2.05 \\
\hline 7 & 4.765 & Sinapyl alcohol & 0.98 & 31 & 15.87 & \begin{tabular}{|l|} 
1,4-Naphthoquinone, \\
2-acetyl-3-hydroxy- \\
5,6,8-trimethoxy-
\end{tabular} & 0.64 \\
\hline 8 & 5.302 & Crypton & 5.86 & 32 & 15.94 & Fisetin & 0.74 \\
\hline 9 & 5.782 & Isopinocampheol & 0.98 & 33 & 16.087 & Ferulic acid & 0.63 \\
\hline 10 & 6.292 & 4-Mercaptophenol & 0.76 & 34 & 16.392 & Resveratrol & 0.7 \\
\hline 11 & 6.539 & Triacetic acid lactone & 2.67 & 35 & 16.581 & $\beta$-Citronellol & 0.71 \\
\hline 12 & 7.003 & Hydroquinone & 4.86 & 36 & 16.908 & Dihydrocarvone & 0.54 \\
\hline 13 & 7.519 & $\begin{array}{l}\text { ENDO, ENDO-2,3- } \\
\text { BORNANEDIOL }\end{array}$ & 0.61 & 37 & 16.972 & Patchoulol & 1.21 \\
\hline 14 & 7.816 & Isobornyl acetate & 1.05 & 38 & 17.132 & \begin{tabular}{|l|}
$5,7,3^{\prime}, 4^{\prime}-$ \\
Tetrahydroxyflavone \\
\end{tabular} & 0.61 \\
\hline 15 & 8.332 & Apigenin 7-glucoside & 1.9 & 39 & 17.211 & $\begin{array}{l}\text { Chromone,5- } \\
\text { hydroxy-6,7,8- } \\
\text { trimethoxy-2,3- } \\
\text { dimethyl- } \\
\end{array}$ & 0.42 \\
\hline 16 & 8.653 & Dihydrouracil & 1.15 & 40 & 17.43 & $\alpha$-Bisabolol & 0.65 \\
\hline 17 & 8.879 & Phloroglucinol & 0.63 & 41 & 17.312 & Isolongifolol & 0.54 \\
\hline 18 & 9.343 & Cumaldehyde & 0.77 & 42 & 20.974 & Genistin & 0.67 \\
\hline 19 & 9.416 & 3-(2-Hydroxyethyl) indole & 1.34 & 43 & 21.063 & Glycitein & 0.67 \\
\hline 20 & 9.682 & Benzoic acid & 1.83 & 44 & 21.389 & Quercetin & 0.44 \\
\hline 21 & 10.332 & 4-Hydroxyphenylpyruvic acid & 0.68 & 45 & 21.491 & Vanylglycol & 0.44 \\
\hline 22 & 11.471 & 2,6-Dihydroxypurine & 1.48 & 46 & 22.043 & $\begin{array}{l}\text { Quercetin 3-D- } \\
\text { galactoside }\end{array}$ & 0.54 \\
\hline 23 & 11.682 & (+)-a-Tocopherol & 1.52 & 47 & 22.959 & Propyl gallate & 0.58 \\
\hline 24 & 12.14 & $\beta$-Resorcylaldehyde & 0.93 & 48 & 23.995 & $\begin{array}{l}\text { 2,3,5,5,8a- } \\
\text { Pentamethyl-6,7,8a- } \\
\text { tetrahydo-5H- } \\
\text { chromen-8-ol }\end{array}$ & 0.62 \\
\hline
\end{tabular}




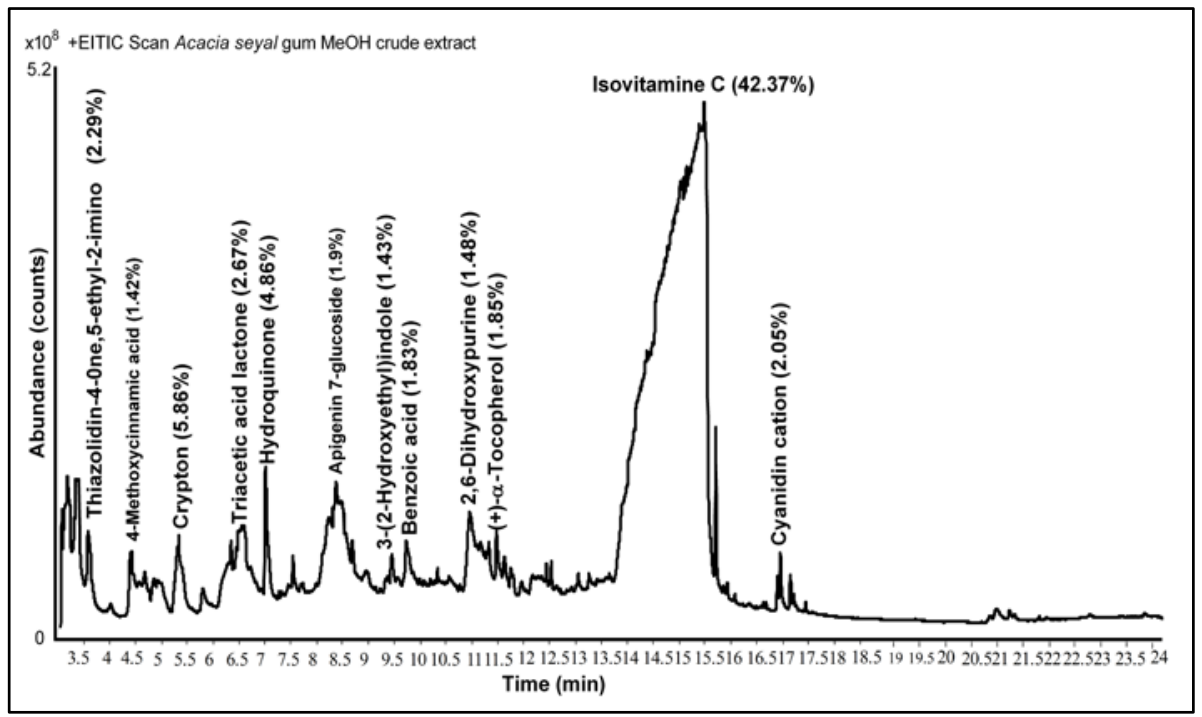

Figure 4. Chromatogram of Acacia seyal gum extract (Rt, 7, 8.5, 11, and $15.5 \mathrm{~min}$ ) respectively, using optimum conditions to detect the bioactive compounds achieved by GC- MS/MS.

\section{CONCLUSIONS}

In this study, the response surface methodology (RSM) using composite central design (CCD) technique was effectively deployed for the optimization of the ultrasonic extraction parameters in the extraction of antioxidants and functional components from Acacia seyal gum. Ultrasonic temperature, power, and time of extraction were found to have different degrees of impact on the extraction process. The parameters significantly affected the response of DPPH, FRAP, and TPC assays. However, temperature increase was found to be insignificant but rather impacted negatively on the antioxidant activity. The optimum ultrasonic extraction conditions for the maximum recovery of antioxidant activity from ASG extract were found to be a time of 3 hours, a power of $40 \mathrm{kHz}$ (3-level), and temperature of $42.50^{\circ} \mathrm{C}$. As a result, forty-eight bioactive compounds were separated from the ASG extract which demonstrates a significant improvement in previous works. Overall, the study has also demonstrated the importance of ultrasonic-assisted extraction (UAE) which is a green approach to the preparation of rich natural antioxidants and functional components from ASG. It is hoped that this study will provide a sufficient foundation for the replacement of synthetic antioxidants. There could be enormous potential for direct utilization of the bioactive component of Acacia seyal gum in the food and pharmaceutical industries. 


\section{EXPERIMENTAL SECTION}

\section{MATERIAL PREPARATION}

Raw gum exudates used in this study were collected from the Blue Nile State of Sudan and validated for identity and purity by experts from the Sudanese Ministry of Forestry and Agriculture. To ensure the homogeneity of the samples, each nodule was randomly selected and prepared in two pieces, and each piece was rendered into powered form by mechanical grounding and sieving using the U.S.A standard testing sieve (Fisher Company) with $1.40 \mathrm{~mm}$ (0.0555 inches) mish size. By using Glossaries (DHAUS sensitive balance with $20 \mathrm{ml}$ capacity in each vial), 1gram of gum powder was measured from the powder samples and a $10 \mathrm{~mL}$ of absolute methanol added to it in a vial. All vials containing samples and solvent were then placed inside the Ultrasonic Water Bath (JAC, SN: RD02AB109x) and centrifuged for 10 minutes at a stirring speed of $1000 \mathrm{rpm}$. At the end of the procedure, a filtering process is applied to the clarified suspension using Sartorius PTEF $0.45 \mu \mathrm{m}$ filter and th supernatants were stored in a freezer below $-25^{\circ} \mathrm{C}$ until further analysis.

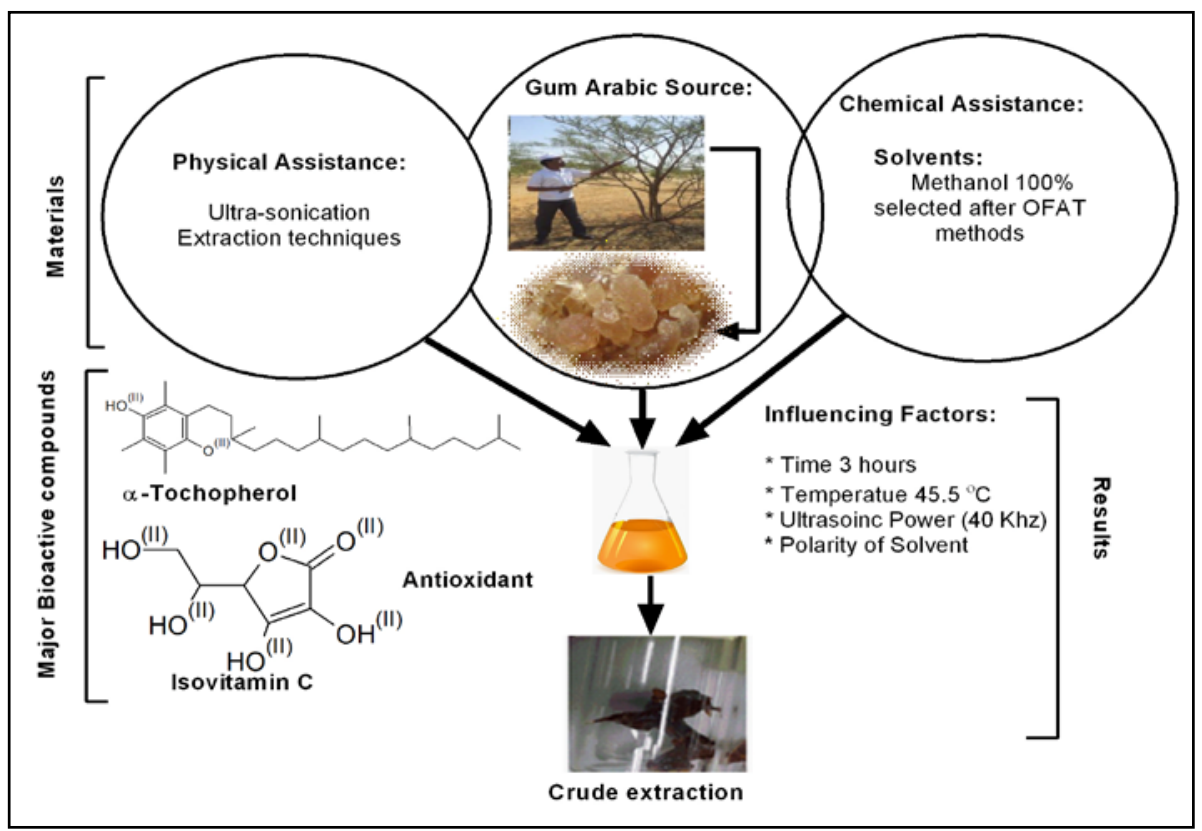

Figure 5. Gum Arabic (Acacia seyal gum), techniques of crude extraction and characterization. 


\section{CHEMICALS AND REAGENTS}

The chemicals and reagents used in the study include folin-ciocalteu phenol reagent, ferric chloride $\left(\mathrm{FeCl}_{3} \cdot 6 \mathrm{H}_{2} \mathrm{O}\right)$, and $\mathrm{HCl}$ obtained from Merck (Darmstadt, Germany). Others include 2, 2-diphenyl-1-picrylhydrazyl (DPPH), 2, 4, 6-tris (2- pyridyl)-s-triazine (TPTZ), Gallic acid, Trolox, and sodium acetate trihydrate from Sigma (USA). Sodium carbonate from RDH (Germany) and glacial acetic acid from Mallinckrodt Baker (USA) was also used. All chemicals and reagents were of analytical grade. Spectrophotometric measurements were done using Spectro Star Nano-spectrophotometer with microplate which contained 96 micro-cuvettes.

\section{ULTRASONIC-ASSISTED EXTRACTION (UAE)}

For the extraction of the bioactive component using UAE, methanol is chosen as the extraction solvent based on cues from preliminary studies which indicated that methanol gives the highest extraction of polyphenols and antioxidant activities. A sample-to-solvent ratio of $1 \mathrm{gram}$ in $10 \mathrm{~mL}$ is adopted to minimize the energy required for heating up the solvent, and also to minimize the energy utilized during solvent removal in the drying process to obtain the bioactive gum powder. All the ultrasonic extraction processes were conducted using an ultrasonic bath (JAC 1505, AC220 V, 60 Hz, 280w, SN: RD 02AB109x, Korea) at the pre-determined conditions designed by the Response Surface Methodology for time, power and temperature. After the extraction process is completed, the extracts are transferred immediately to an ice bath to cool to room temperature. Consequently, a filtering procedure is applied to the clarified suspension by means of a Sartorius PTEF $0.45 \mu \mathrm{m}$ filter, and the supernatants are stored in a freezer below $-25^{\circ} \mathrm{C}$ until the analysis was conducted.

\section{EXPERIMENTAL DESIGN}

The experimental design in this study is based on the response surface methodology (RSM) technique. RSM explores, by careful experimental design, the influence of several independent variables (input variables) on one or more response variables (output variables) with the objective of obtaining optimized output responses. Under the RSM, the popular Box-Wilson procedure, commonly called Central Composite Design (CCD) is adopted to evaluate the relevance of the three controllable factors (namely ultrasonic power, temperature and ultra-sonication duration) in the extraction process, and to identify eventual interactions between the variables.

CCD consists of a set of factorial or fractional factorial designed with center points for estimation of curvatures. A two-level full factorial design (coded \pm 1 ), superimposed by center points (coded 0 ) and "star points" (coded $\pm a$ ) can be used which permits shortening of the number of experiments. 
"Star points" are axial experiments located on variable axes at a distance from the reference center. They establish new extremes for the parameters of the factors involved which provide the basis for the estimation of curvatures for the model. The value of star points is a function of the desired properties of the experimental design and also of the number of experiments involved in the model. A virtual cube can be imagined where each axis of the cube corresponds to a variable under study. In the experimental analysis, the central composite design points describe a sphere around the factorial cube. Preliminary experiments allow pointing the variables at five different coded levels: $-\alpha(=1.68)$, $1,0,+1,+\alpha(=+1.68)$.

A total of 20 experiments were conducted including six replications at the center point to evaluate experimental error. The independent variables are the extraction temperature, $25-60{ }^{\circ} \mathrm{C}$, extraction time, 1-3 hours, and ultrasonic power was $12-40 \mathrm{kHz}$ (or Low to high level coded 1-3). The coded values of the independent variables for $C C D$ are shown in Table 7. Total phenolic (TPC), DPPH and FRAP were selected as the response of the design experiments $(Y)$. Table 7 shows the coded and actual values for CCD of the independent variables.

The model equations, 3D graph plots, and the 2D contour plots were developed using the design of experiment (DOE) software version ${ }^{\circledR}$ 7.0.0. The software also allows predicting the optimum conditions of the independent variables. A second order equation given in (1) was used to express the level of antioxidant activity and the content of phenolic compounds as a function of the independent variables.

$$
y=\beta 0+\sum_{i=1}^{2} \beta i x i+\sum_{i=1}^{3} \beta i i x_{i}^{2}+\sum_{i=1}^{2} \sum_{i=i+1}^{3} \beta i j x i x j
$$

$\mathrm{Y}$ in the equation is the predicted response which represents the level of antioxidant activity (measured in $\mathrm{mg}$ TE or GAE/100g); $\beta 0$ represent the regression coefficients or intercept; $\beta_{i}$ models the linear effect of the variables, $\beta_{i i}$ represents the squared effect; $\beta_{i j}$ denotes the interaction effect; while $x_{i}$ and $x_{j}$ represent the independent variables affecting the output responses. The experimental data were analysed by the Design-Expert software ${ }^{\circledR}[7.0 .0]$ and the coefficients estimated by means of their F-value. Consequently, to obtain the optimum experimental conditions of total phenolic contents and the level of antioxidant activity, statistical analyses were performed namely analysis of variance (ANOVA), regression analysis, and plotting of response surface figures. 
GUM ARABIC: AN OPTIMIZATION OF ULTRASONIC- ASSISTED EXTRACTION OF ANTIOXIDANT ...

Table 7. The range of coded and actual values for central composite design

\begin{tabular}{|l|c|c|c|c|}
\hline \multirow{2}{*}{ Independent variables } & \multirow{2}{*}{ Code units } & \multicolumn{3}{|c|}{ Coded levels } \\
\cline { 3 - 5 } & & $\mathbf{- 1}$ & $\mathbf{0}$ & $\mathbf{1}$ \\
\hline Extraction Time (Hours) & $x_{1}$ & 1 & 2 & 3 \\
\hline Power (kHz) & $x_{2} X_{2}$ & 12 & 26 & 40 \\
\hline Temperature $\left({ }^{\circ} \mathrm{C}\right)$ & $x_{3}$ & 25 & 42 & 60 \\
\hline
\end{tabular}

\section{ANTIOXIDANT ACTIVITY DETERMINATION}

\section{DETERMINATION OF FOLIN-CIOCALTEU INDEX FOR TPC}

For determination of TPC, the folin-Ciocalteu index $(\mathrm{FCl})$ assay was used. The procedure adopted follows the method described by [46, 47]. Approximately $0.5 \mathrm{~mL}$ diluted Folin-Ciocalteu reagent was added to $100 \mu \mathrm{L}$ sample extracts and allowed to set for 5 minutes before addition of $1 \mathrm{~mL}(7.5 \%)$ of sodium carbonate $(\mathrm{w} / \mathrm{v})$. The absorbance was taken at $765 \mathrm{~nm}$ wavelength using the spectrophotometer after $2 \mathrm{~h}$, and the result recorded in terms of $\mathrm{mg}$ of Gallic acid equivalent (GAE).

\section{RADICAL SCAVENGING ACTIVITY (DPPH)}

A 2, 2-diphenyl-1-picrylhydrazyl (DPPH) was used to evaluate the antioxidant activity. This is based on the method presented by Musa, Abdullah, Kuswandi, and Hidayat [48]. The DPPH was freshly produced by liquefying 40 $\mathrm{mg} \mathrm{DPPH}$ in $1000 \mathrm{ml}$ of methanol to get a $1.00 \pm 0.01$ unit of absorbance in a spectrophotometer (Spectro Nanostar, Germany) at $517 \mathrm{~nm}$ wavelength. Before keeping it in the dark for 2 hours, approximately $100 \mu \mathrm{L}$ of sample were mixed up with $1 \mathrm{ml}$ of the DPPH solution. Equation (2) presents the determination rules of the DPPH scavenging activity.

$$
\% D P P H_{s c}=\left(A_{\text {con }}-A_{\text {sample }}\right) \times 100 / A_{\text {con }}
$$

Where; $A_{\text {con }}$ and $A_{\text {sample }}$ represent the absorbance of the control and sample respectively.

\section{DETERMINATION OF FERRIC REDUCING ANTIOXIDANT POWER (FRAP)}

A working fresh FRAP reagent was prepared as described by [48] with some slight modification. The working reagent is formulated by mixing $300 \mathrm{~mm}$ acetate buffer having pH3.6 (constituted by $3.1 \mathrm{~g}$ sodium acetate trihydrate plus $16 \mathrm{ml}$ glacial acid) with distilled water in a ratio 1:1; plus $10 \mathrm{~mm}$ TPTZ (2,4,6tris (2-pyridyl)-s-triazine) in $40 \mathrm{~mm} \mathrm{HCL}$; and with $20 \mathrm{~mm} \mathrm{FeCl} 3 \cdot 6 \mathrm{H} 2 \mathrm{O}$ in the 
ratio of 10:1:1. After 30 minutes, about $1 \mathrm{ml}$ of FRAP reagent was added to 100 $\mu \mathrm{L}$ of samples. By using a spectrophotometer, the absorbance was placed at $595 \mathrm{~nm}$ wavelength, and the experimental result presented in milligram $(\mathrm{mg})$ of Trolox equivalent (TE) per $100 \mathrm{~g}$ of fresh sample (mg TE/100 $\mathrm{g}$ of FW).

\section{GC-MSIMS ANALYSIS}

GC-MS/MS analysis was used to identify compounds in the extracted Acacia seyal gum (ASG), in accordance with the method reported by StankovJovanović et al. [49]. The analysis was carried out using a GC (from Agilent Technologies 7890A) interfaced with a mass-selective detector (MSD) (Agilent 7000 Triple Quad). The MSD is equipped with Agilent HP-5ms (5\%-phenyl methyl polysiloxane) capillary column with dimension $30 \mathrm{~m} \times 0.25 \mathrm{~mm}$ i. d. and $0.25 \mu \mathrm{m}$ film thickness. The carrier gas used is helium which has a linear velocity of $1 \mathrm{ml} / \mathrm{min}$. Injector and detector temperatures were at $200^{\circ} \mathrm{C}$ and $250{ }^{\circ} \mathrm{C}$, respectively, and the volume of the injected sample was $1 \mu \mathrm{l}$. The MS operating parameters were given as: ionization potential, $70 \mathrm{eV}$, interface temperature, $250^{\circ} \mathrm{C}$, and acquisition mass range, 50-600. Consequently, the identification of components was done by comparison of their mass spectra and retention time with those of the authentic/standard compounds; by computer matching with NIST and WILEY library; and by comparison of the fragmentation pattern of the mass spectral data with those reported in the literature.

\section{ACKNOWLEDGMENTS}

The authors would like to acknowledge express their gratitude to the Department of Biotechnology Engineering (BTE), Faculty of Engineering at the International Islamic University Malaysia (IIUM) and the International Institute for Halal Research and Training (INHART) at IIUM. The $1^{\text {st }}$ author would like to express his gratitude to Dr. Elbasheir Sallam for his continuous and unlimited financial support in conducting this research.

\section{REFERENCES}

1. D. Anderson, Forest Ecology and Management, 1993, 58.

2. B. Elmqvist, L. Olsson, E.M. Elamin, A. Warren, Agroforestry systems, 2005, 64.

3. A. Islam, G. Phillips, A. Sljivo, M. Snowden, P. Williams, Food Hydrocolloids, 1997,11. 
GUM ARABIC: AN OPTIMIZATION OF ULTRASONIC- ASSISTED EXTRACTION OF ANTIOXIDANT ...

4. G.A. Yasseen, A.A. Salih, M.E. Ahmed, Procedia-Social and Behavioral Sciences, 2014,120.

5. S. Al Assaf, G.O. Phillips, P.A. Williams, Food Hydrocolloids, 2005,19.

6. B.H. Ali, S. Beegam, I. Al-Lawati, M. Waly, M. Al Za'abi, A. Nemmar, Physiological Research, 2013, 62.

7. J.W. Bainbridge, A.J. Smith, S.S. Barker, S. Robbie, R. Henderson, K. Balaggan, A. Viswanathan, G.E. Holder, A. Stockman, N. Tyler, New England Journal of Medicine, 2008, 358.

8. A.A.H.M. Elnour, Fractionation; Physicochemical and Functional Properties of Acacia Polyacantha Gum, in, UOFK, 2015.

9. B.H. Ali, M.S. Al Moundhri, Food and Chemical Toxicology, 2006, 44.

10. J.A. Hinson, A.B. Reid, S.S. McCullough, L.P. James, Drug Metabolism Reviews, 2004, 36.

11. H. Trommer, R.H. Neubert, International Journal of Pharmaceutics, 2005,298.

12. C.J. Evans, D. Keith, H. Morrison, K. Magendzo, R.H. Edwards, SCIENCE-NEW YORK THEN WASHINGTON-, 1992, 258.

13. A. Tiss, F. Carrière, R. Verger, Analytical Biochemistry, 2001, 294.

14. B.H. Ali, G. Blunden, M.O. Tanira, A. Nemmar, Food and chemical Toxicology, 2008, 46.

15. D.Z. Bliss, T.P. Stein, C.R. Schleifer, R.G. Settle, The American journal of clinical nutrition, 1996,63.

16. N. Matsumoto, S. Riley, D. Fraser, S. Al-Assaf, E. Ishimura, T. Wolever, G. Phillips, A.O. Phillips, Kidney international, 2006, 69.

17. D.A. Glover, K. Ushida, A.O. Phillips, S.G. Riley, Food Hydrocolloids, 2009, 23.

18. K.U. Rehman, M.A. Wingertzahn, S. Teichberg, R.G. Harper, R.A. Wapnir, Digestive diseases and sciences, 2003, 48.

19. R.A. Wapnir, B. Sherry, C.N. Codipilly, L.O. Goodwin, I. Vancurova, Digestive diseases and sciences, 2008, 53.

20. F. Chemat, M.A. Vian, G. Cravotto, International journal of molecular sciences, 2012, 13.

21. F. Fathordoobady, H. Mirhosseini, J. Selamat, M.Y.A. Manap, Food Chemistry, 2016, 202.

22. H.K. Kala, R. Mehta, K.K. Sen, R. Tandey, V. Mandal, Trends in Analytical Chemistry, 2016, 85, Part C.

23. D.-P. Xu, J. Zheng, Y. Zhou, Y. Li, S. Li, H.-B. Li, Food Chemistry, 2017, 217.

24. M. Mushtaq, B. Sultana, F. Anwar, A. Adnan, S.S.H. Rizvi, The Journal of Supercritical Fluids, 2015, 104.

25. F. Chemat, G. Cravotto, "Enhancing Extraction Processes in the Food Industry", CRC Press, Taylor and Francis Group, Boca Raton, London, New York, 2011, chapter 6.

26. F. Chemat, N. Rombaut, A.-G. Sicaire, A. Meullemiestre, A.-S. Fabiano-Tixier, M. Abert-Vian, Ultrasonics Sonochemistry, 2017, 34.

27. E. Roselló-Soto, C.M. Galanakis, M. Brnčić, V. Orlien, F.J. Trujillo, R. Mawson, K. Knoerzer, B.K. Tiwari, F.J. Barba, Trends in Food Science \& Technology, 2015, 42. 
28. G. Ruiz-Montañez, J. Ragazzo-Sánchez, M. Calderón-Santoyo, G. VelazquezDe La Cruz, J.R. de León, A. Navarro-Ocaña, Food chemistry, 2014, 159.

29. L. Wang, C.L. Weller, Trends in Food Science \& Technology, 2006, 17.

30. R.H. Myers, D.C. Montgomery, C.M. Anderson-Cook, Response surface methodology: process and product optimization using designed experiments, John Wiley \& Sons, 2016.

31. K. Chaisu, A.L. Charles, Y.-K. Guu, T.-B. Yen, C.-H. Chiu, APCBEE procedia, 2014, 8.

32. M. Chen, Y. Zhao, S. Yu, Food chemistry, 2015, 172.

33. C. Kotzamanidis, T. Roukas, G. Skaracis, World Journal of Microbiology and Biotechnology, 2002, 18.

34. R.S. Makkar, S.S. Cameotra, I.M. Banat, AMB express, 2011, 1.

35. L.V. Candioti, M.M. De Zan, M.S. Cámara, H.C. Goicoechea, Talanta, 2014, 124.

36. Z. Šumić, A. Vakula, A. Tepić, J. Čakarević, J. Vitas, B. Pavlić, Food Chemistry, 2016, 203.

37. Y. Yuan, Y. Gao, L. Mao, J. Zhao, Food Chemistry, 2008, 107.

38. E. Dorta, M.G. Lobo, M. González, LWT-Food Science and Technology, 2012, 45.

39. F.B. Abdelaal, R.K. Rowe, Geotextiles and Geomembranes, 2014, 42.

40. Y.-Q. Ma, J.-C. Chen, D.-H. Liu, X.-Q. Ye, Ultrasonics Sonochemistry, 2009, 16.

41. M. Esclapez, J. García-Pérez, A. Mulet, J. Cárcel, Food Engineering Reviews, 2011, 3.

42. M.N. Alam, N.J. Bristi, M. Rafiquzzaman, Saudi Pharmaceutical Journal, 2013, 21.

43. J. Kubola, S. Siriamornpun, Food Chemistry, 2008, 110.

44. W. Greenaway, F.R. Whatley, Phytochemistry, 1991, 30.

45. S. Fiorito, V.A. Taddeo, S. Genovese, F. Epifano, Tetrahedron Letters, 2016, 57.

46. K.H. Musa, A. Abdullah, K. Jusoh, V. Subramaniam, Food Analytical Methods, 2011, 4.

47. Q.V. Vuong, C.D. Goldsmith, T.T. Dang, V.T. Nguyen, D.J. Bhuyan, E. Sadeqzadeh, C.J. Scarlett, M.C. Bowyer, Antioxidants, 2014,3.

48. K.H. Musa, A. Abdullah, B. Kuswandi, M.A. Hidayat, Food chemistry, 2013,141.

49. V. Stankov-Jovanović, M. Ilić, V. Mitić, T. Mihajilov-Krstev, S. Simonović, S.N. Mandić, J. Tabet, R. Cole, Journal of pharmaceutical and biomedical analysis, $2015,111$. 